\title{
Enhanced application limits for crossed helical gearboxes using new geometries for smaller sliding paths or smaller contact pressures
}

\author{
Christoph Boehme ${ }^{1 *}$, Dietmar Vill ${ }^{1}$, Peter Tenberge ${ }^{1}$ \\ ${ }^{1}$ Ruhr-University Bochum, Chair of Industrial and Automotive Drivetrains, 44801 Bochum, Germany
}

\begin{abstract}
Crossed-axis helical gear units are used as actuators and auxiliary drives in large quantities in automotive applications such as window regulators, windscreen wipers and seat adjusters. Commonly gear geometry of crossed helical gears is described with one pitch point. This article deals with an extended calculation method for worm gear units. The extended calculation method increases the range of solutions available for helical gears. In general, for a valid crossed helical gear pair, the rolling cylinders do not have to touch each other. In mass production of many similar gears, individual gears can be reused because they can be paired with other centre distances and ratios. This also allows the use of spur gears in combination with a worm, making manufacturing easier and more efficient. By selecting design parameters, for example the axis crossing angle or the helix angle of a gear, positive effects can be achieved on the tooth contact pressure, the overlap ratio, the sliding paths, the lubrication condition, the tooth stiffness and, to a limited extent, on the efficiency of the gearing. It can be shown that for involute helical gears, in addition to the known insensitivity of the transmission behaviour to centre distance deviations, there is also insensitivity to deviations of the axis crossing angle. This means that installation tolerances for crossed helical gearboxes can be determined more cost-effectively.
\end{abstract}

\section{Introduction}

Crossed-axis helical gear pairs frequently are used as actuators and auxiliary drives in automotive applications such as window regulators, windscreen wipers and seat adjusters. Fig. 1 shows an example application from an electric flap actuator of an internal combustion engine according to VDI 2736 [2]. Niemann [1] describes the gear geometry of helical gears with one pitch point. VDI Guideline 2736 [2] also presumes a pitch point. This article deals with an extended calculation method for worm gear units that increases the range of solutions available for helical gears. Also, various advantages can be achieved, that will be shown later.

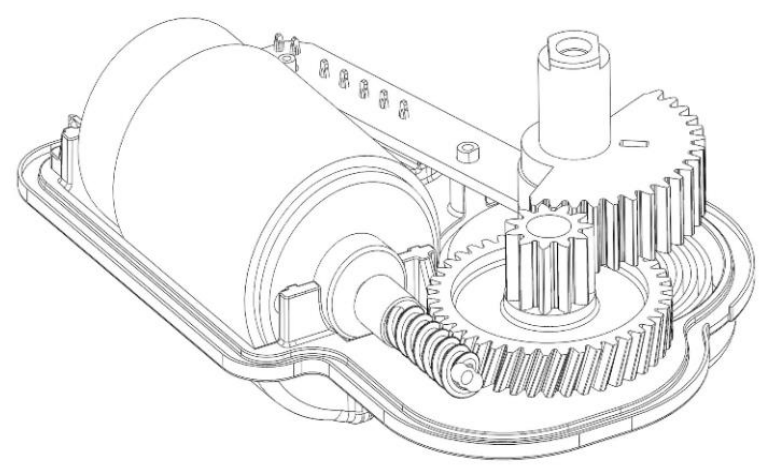

Fig. 1. Crossed-axis helical gear unit in an electric flap actuator of a combustion engine [2]

\footnotetext{
Corresponding author: christoph.boehme-g9j@rub.de
}

\section{Calculation}

Figure 2 shows the basic idea of Niemann [1] for the analysis of the meshing geometry of crossed helical gears. The axes of two wheels cross under the angle $\Sigma$ and have the centre distance a. The mid plane of a face gear is located between the axles. The face gear has the usual profile geometry for the generation of helical involute gears.

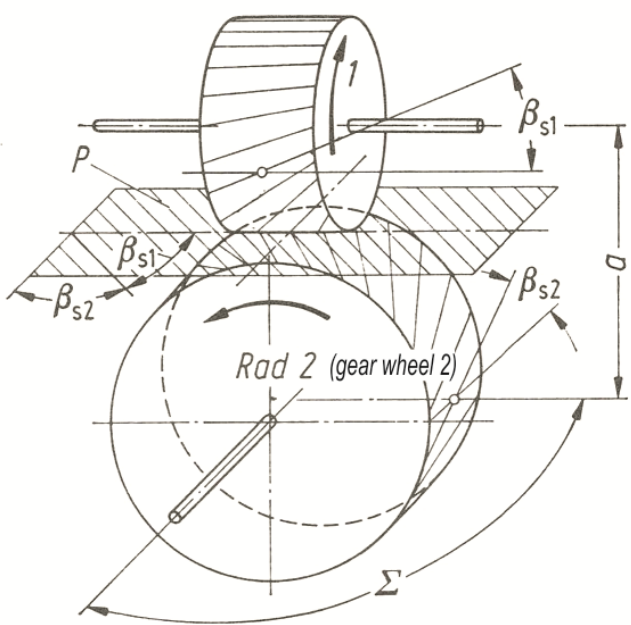

Fig. 2. Diagram of the tooth engagement of a crossed helical gearbox [1]

In the transverse sections of the two gears, a pinion profile and a spur gear with involute flanks mesh with each other in plane perspective. 

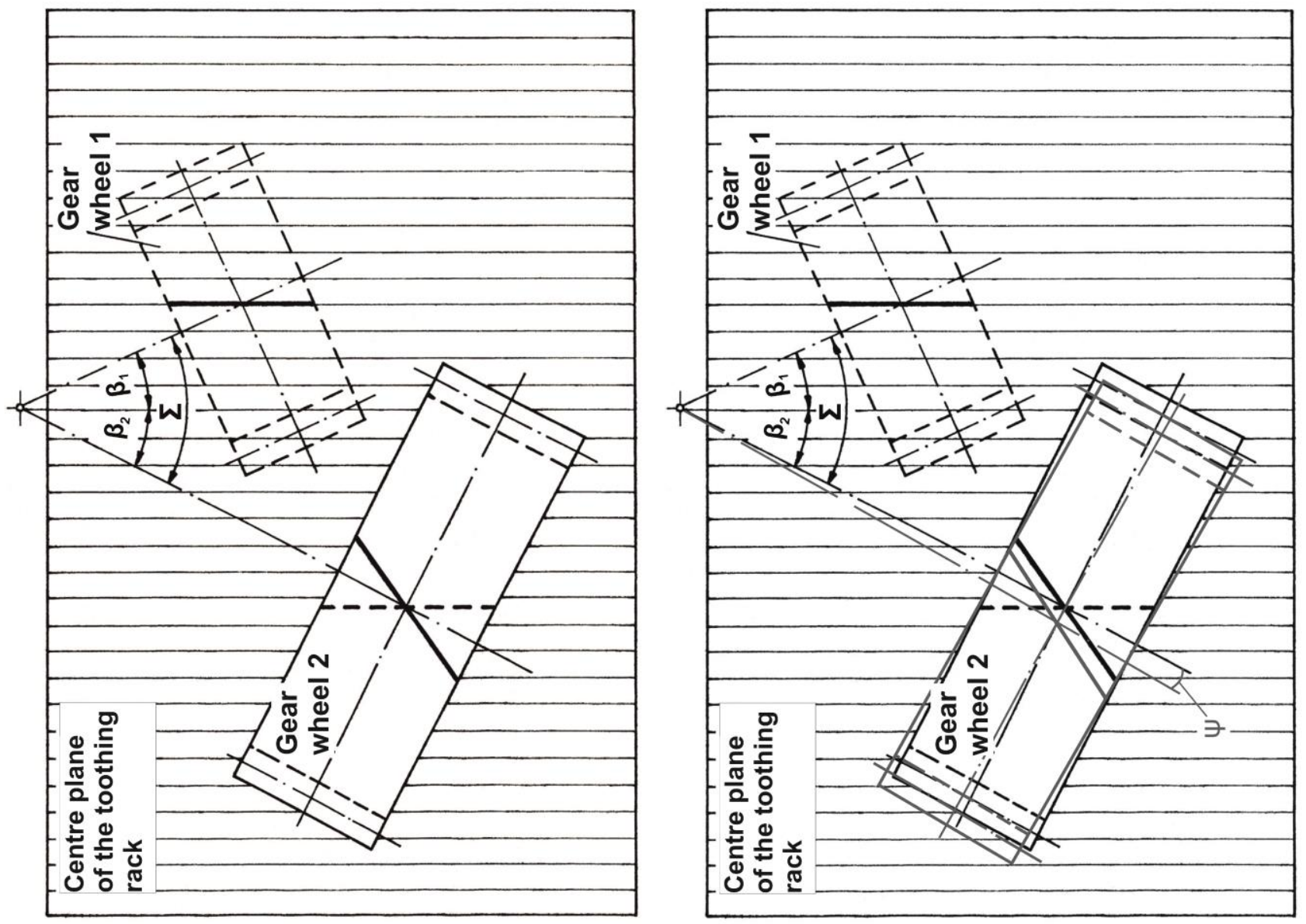

Fig. 3. Schematic diagram of a crossed helical gear unit with face toothing in plain view

The rolling geometry in the two transverse sections defines a rolling circle for both wheels and a rolling cylinder in a spatial view. The rolling cylinders touch at one point. Niemann defines this point as pitch point and the rolling cylinders as pitch cylinders. The helix angles of the two wheels at the pitch cylinders add up to the axis crossing angle.

Figure 3 illustrates this concept using a top view of the gearbox. Here it becomes visible that the common gear pairs with parallel axes are a special case of a more general consideration.

The transmission behaviour between the face gear and a spur gear generated by this is ideally uniform. This also ensures the uniform transmission between the two spur gears.

The two spur gears mesh as a gear pair because each gear wheel meshes with the generating face toothing. The meshing geometry of the two gears can be derived from their meshing with the face toothing.

In the extended consideration, the rolling cylinders do not have to touch each other. In the transverse sections of the two wheels, the arbitrarily defined face toothing first produces a toothed rack that meshes with a spur gear in a profile-shifted manner. The rolling movement can be described by rolling a straight line on a rolling circle. The following calculation process starts with the basic definition of 2 spur gears and then analyses the tooth mesh. A common generating profile $\mathrm{Q}$ is then calculated for this meshing.

\subsection{Basics of the calculation process}

First, the centre distance a and the axis crossing angle $\Sigma+\psi$ must be selected. The definition of the axis crossing angle as the sum of two angles considers the frequent standard case of perpendiculary crossed axes as described for example from Wassermann [4]. It is always $\Sigma=90^{\circ}$ and the angle $\psi$ describes the deviation of the axis crossing angle from $90^{\circ}$.

Furthermore, a common normal modulus $\mathrm{m}_{\mathrm{n}}$ and a pressure angle in normal section $\alpha_{n}$ must be selected. The basic data of the gears consist of the number of teeth $\mathrm{z}_{1,2}$, the helix angles at the pitch circle $\beta_{1,2}$ and the profile shift factor $\mathrm{x}_{1}$ for gear 1 . With these data the base circle helix angles $\beta_{\mathrm{b} 1,2}$ can be calculated.

The next step is to determine the common generating profile $\mathrm{Q}$ of both gears as face toothing in tooth engagement. Figure 4 shows the basic definitions.

The $\mathrm{x}, \mathrm{y}, \mathrm{z}$ coordinate system is a global system and is identical to the body coordinate system $\mathrm{x}_{1}, \mathrm{y}_{1}, \mathrm{z}_{1}$ for gear 1 . The $\mathrm{x}$-axis corresponds to the rotation axis of wheel 1 , the $\mathrm{z}$-axis is the perpendicular of the wheel axes and the $y$-axis completes the orthogonal system. The $y_{2}$ axis defines the rotation axis of wheel 2 . The $z_{2}$ axis points from the centre of wheel 2 against the direction of the $z_{1}$ axis. The $\mathrm{x}_{2}$-axis completes the body coordinate system of wheel 2. Coordinates relative to the system 2 are 


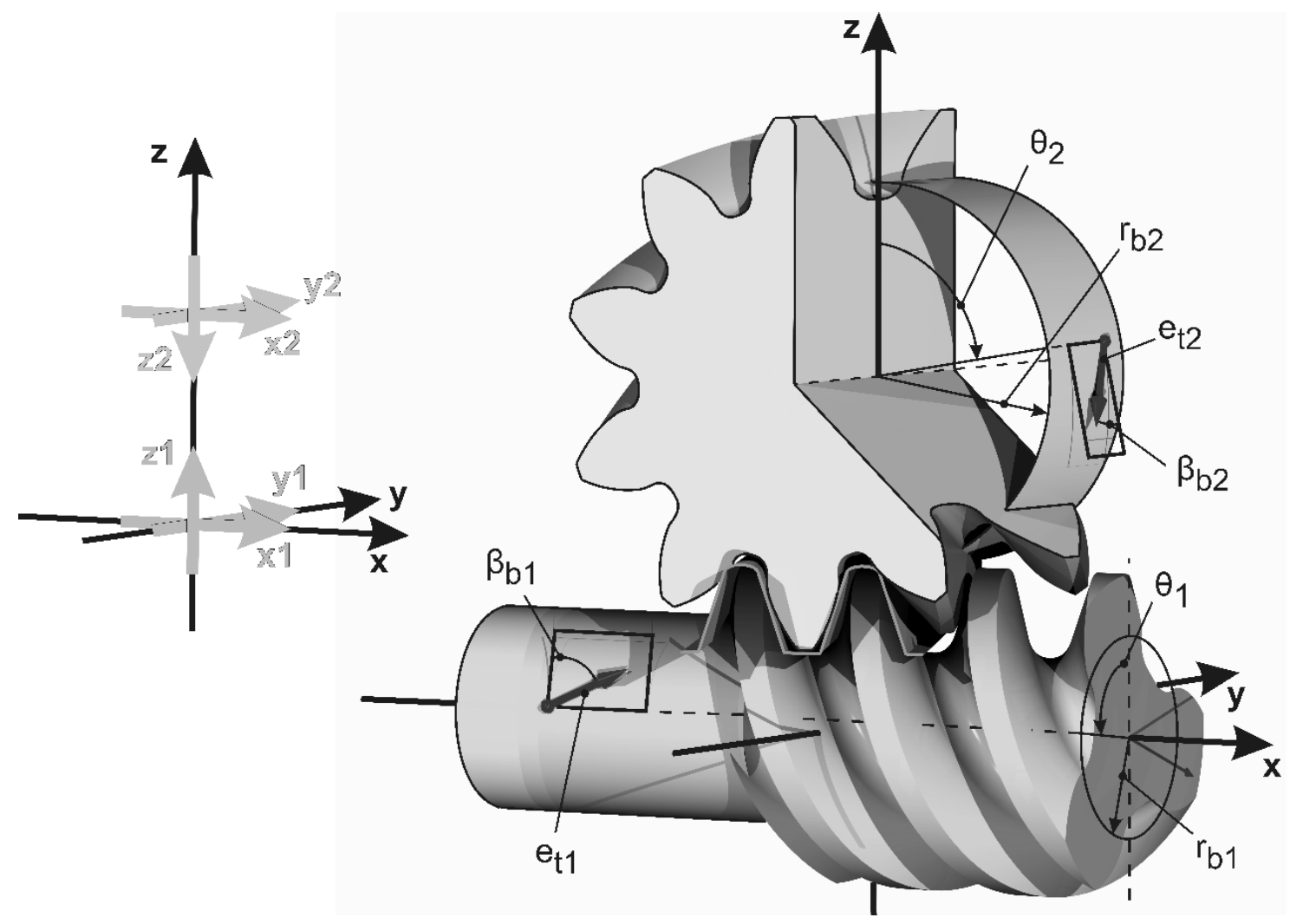

Fig. 4. Schematic representation of the tooth engagement in a helical gear unit

subsequently marked with the index suffix "2". Figure 4 shows two gears meshing. In a contact point, there is a common tangential plane with a common normal vector for both gears. Each normal vector on an involute flank points tangentially to the base cylinder.

Compared to the face section at the tangential point, the normal vector includes the base cylinder helix angle $\beta_{\mathrm{b} 1,2}$.

Figure 4 also shows the unit vectors $\overline{\mathrm{e}}_{\mathrm{t} 1}$ and $\overline{\mathrm{e}}_{\mathrm{t} 2}$ in a general position. These vectors affect the respective base cylinder and include the base cylinder helix angle $\beta_{\mathrm{b} 1,2}$ in relation to a face section at the tangential point.

The general position is defined by the face section at the tangential point and the position angle $\theta_{1,2}$.

Now rules for the calculation of the path of contact can be derived. In the first step, the two parameters $\theta_{1}$ and $\theta_{2}$ are calculated, so that the unit vectors $\overline{\mathrm{e}}_{\mathrm{t} 1}$ and $\overline{\mathrm{e}}_{\mathrm{t} 2}$ are directed exactly against each other. After that, these are direction vectors on the path of contact.

The equations for the description of the unit vectors are as follows.

$$
\begin{gathered}
\overline{e_{t 1}}=\left(\begin{array}{c}
e_{t 1 x} \\
e_{t 1 y} \\
e_{t 1 z}
\end{array}\right)=\left(\begin{array}{c}
\sin \left(\beta_{b 1}\right) \\
\cos \left(\theta_{1}\right) \cdot \cos \left(\beta_{b 1}\right) \\
\sin \left(\theta_{1}\right) \cdot \cos \left(\beta_{b 1}\right)
\end{array}\right) \\
\overline{e_{t 2 \_2}}=\left(\begin{array}{c}
e_{t 2 x 2} \\
e_{t 2 y 2} \\
e_{t 2 z 2}
\end{array}\right)=\left(\begin{array}{c}
-\cos \left(\theta_{2}\right) \cdot \cos \left(\beta_{b 2}\right) \\
-\sin \left(\beta_{b 2}\right) \\
-\sin \left(\theta_{2}\right) \cdot \cos \left(\beta_{b 2}\right)
\end{array}\right)
\end{gathered}
$$

$$
\overline{e_{t 2}}=\left(\begin{array}{c}
e_{t 2 x} \\
e_{t 2 y} \\
e_{t 2 z}
\end{array}\right)=\left[\begin{array}{c}
\cos (\psi) \cdot\left(e_{t 2 x 2}\right)-\sin (\psi) \cdot\left(e_{t 2 y 2}\right) \\
\sin (\psi) \cdot\left(e_{t 2 x 2}\right)+\cos (\psi) \cdot\left(e_{t 2 y 2}\right) \\
e_{t 2 z 2}
\end{array}\right]
$$

The unit vector $\overline{\mathrm{e}}_{\mathrm{t} 2}$ is first defined in system 2 and transferred to the global system via a rotation matrix. The alignment of the vectors against each other requires the fulfilment of the following equation.

$$
\overline{e_{\mathrm{t} 1}}+\overline{e_{\mathrm{t} 2}}=\overline{0}
$$

The angles $\theta_{1}$ and $\theta_{2}$ can be determined by resolving the equation system in equation (4).

$$
\begin{aligned}
& \theta_{1}=\operatorname{acos}\left[\frac{\sin (\psi) \cdot\left(\sin \left(\beta_{\mathrm{b} 1}\right)\right)+\sin \left(\beta_{\mathrm{b} 2}\right)}{\cos (\psi) \cdot \cos \left(\beta_{\mathrm{b} 1}\right)}\right] \\
& \theta_{2}=\operatorname{acos}\left[\frac{\sin (\psi) \cdot\left(\sin \left(\beta_{\mathrm{b} 2}\right)\right)+\sin \left(\beta_{\mathrm{b} 1}\right)}{\cos (\psi) \cdot \cos \left(\beta_{\mathrm{b} 2}\right)}\right]
\end{aligned}
$$

Equations (5) and (6) do not always provide physically meaningful solutions. If the arguments of the acos functions are bigger than 1, the default values do not lead to a meshing wheel pairing. Then there is no possibility to find a common contact plane in a contact point of the tooth flanks in any rotational position of the gears.

\subsection{Determination of the pitch points}

Further calculations are based on Figure 5. The upper illustration shows a toothing with vertically crossed axes 

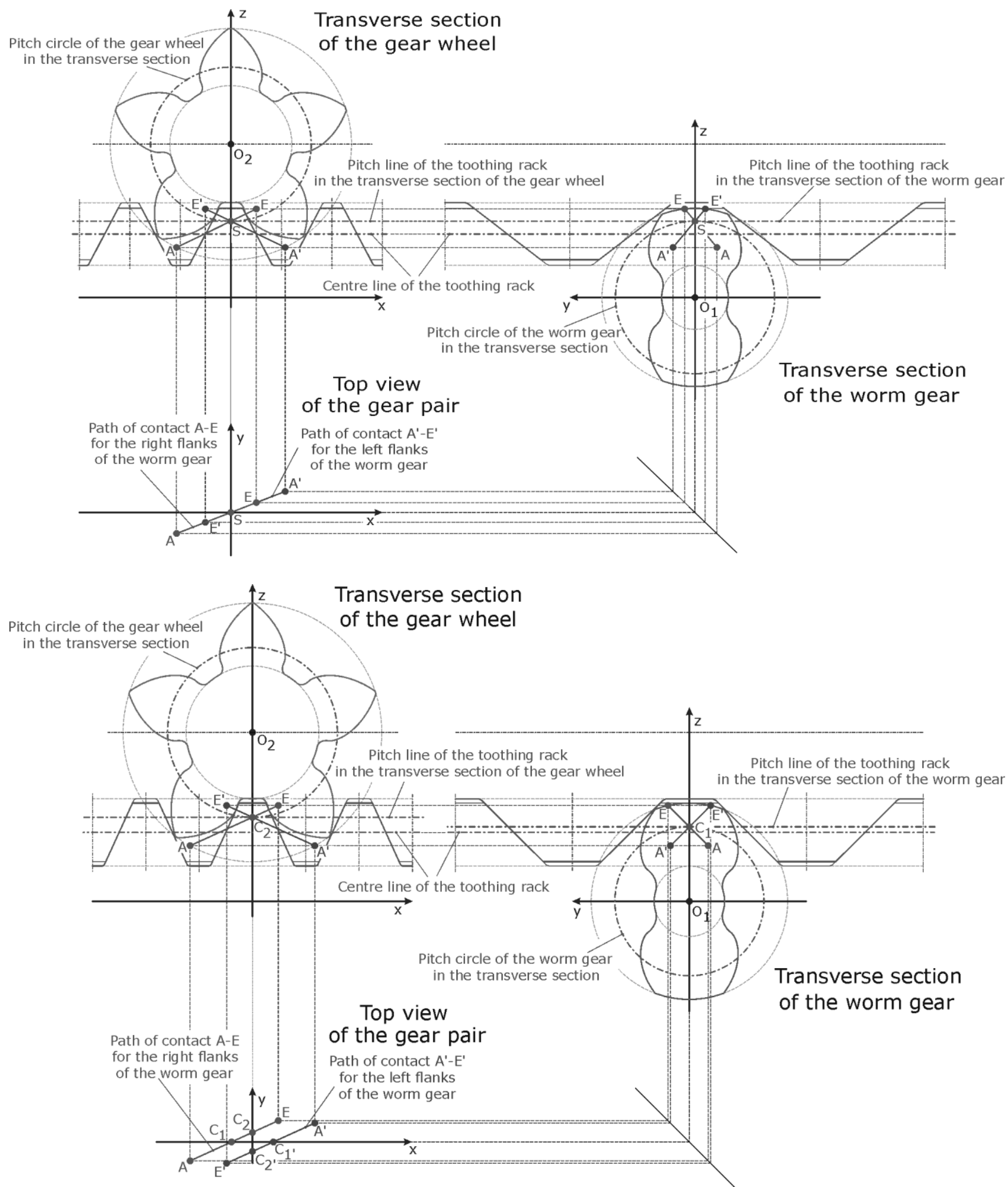

Fig. 5. Face section profile of an example toothing. Above: Toothing with pitch point, below: Wheel 2 with enlarged helix angle

and a pitch point in three views. The two upper views show the face section profiles of the gears and the generating face profile as a rack. In addition to the profile centre line, the pitch circles and pitch lines as well as the paths of contact are shown.

$$
\begin{gathered}
z_{C 1}=\frac{d_{b 1}}{2 \cdot \cos \left(\theta_{1}\right)} \\
z_{C 2}=a-\frac{d_{b 2}}{2 \cdot \cos \left(\theta_{2}\right)}
\end{gathered}
$$


For gear 1 the pitch point $\mathrm{C} 1$ is at $\mathrm{y}$-coordinate 0 , for gear $2 \mathrm{C} 2$ is at $\mathrm{x}_{2}$-coordinate 0 in the corresponding reference system 2 . It leads to the following equations.

$$
\begin{gathered}
y_{C 1}=0 \\
x_{C 2 \_2}=0
\end{gathered}
$$

In the face section of wheel 2 and in system 2 , the $\mathrm{x}_{2}$ coordinate of point $\mathrm{C} 1$ can be calculated from the position of point $\mathrm{C} 2$. Similarly, in the face section of gear 1 in the global system, the y-coordinate of point $\mathrm{C} 2$ can be determined from the position of point $\mathrm{C} 1$. This leads to the following equations.

$$
\begin{gathered}
x_{C 1 \_2}=\frac{{ }^{z_{C 1}-z_{C 2}}}{e_{t 2 z 2}} \cdot e_{t 2 x 2} \\
y_{C 2}=\frac{{ }^{z_{C 2}}-{ }^{z_{C}}{ }_{1}}{e_{t 1 z}} \cdot e_{t 1 y}
\end{gathered}
$$

Now the position of the pitch points is completely determined, but the coordinates are still partly in coordinate system 2 . The transformation from system 2 to system 1 as a global system is described by the following four equations.

$$
\begin{aligned}
& \mathrm{x}_{\mathrm{C} 1}=\cos (\psi) \cdot \mathrm{x}_{\mathrm{C} 1} 2^{-\sin (\psi) \cdot \mathrm{y}_{\mathrm{C} 1} \_2} \\
& \mathrm{y}_{\mathrm{C} 1}=\sin (\psi) \mathrm{x}_{\mathrm{C} 1 \_2^{+}}+\cos (\psi) \cdot \mathrm{y}_{\mathrm{C} 1 \_2} \\
& \mathrm{x}_{\mathrm{C} 2}=\cos (\psi) \cdot \mathrm{x}_{\mathrm{C} 2} 2^{-\sin (\psi) \cdot \mathrm{y}_{\mathrm{C} 2} \_2} \\
& \mathrm{y}_{\mathrm{C} 2}=\sin (\psi) \mathrm{x}_{\mathrm{C} 2 \_2^{+}} \cos (\psi) \cdot \mathrm{y}_{\mathrm{C} 2 \_2}
\end{aligned}
$$

The conversion of equation (14) returns the $\mathrm{y}_{2}$ coordinate of point $\mathrm{C} 1$.

$$
\mathrm{y}_{\mathrm{C1} 22}=\frac{\mathrm{y}_{\mathrm{C} 1}-\sin (\psi) \cdot \mathrm{x}_{\mathrm{C} 1 \_2}}{\cos (\psi)}
$$

Accordingly, equation (16) is followed by the $y_{2}$ coordinate of point $\mathrm{C} 2$.

$$
\mathrm{y}_{\mathrm{C} 2 \_2}=\frac{\mathrm{y}_{\mathrm{C} 2}-\sin (\psi) \cdot \mathrm{x}_{\mathrm{C} 2 \_2}}{\cos (\psi)}
$$

This allows to calculate the positions of the pitch points $\mathrm{C} 1$ and $\mathrm{C} 2$ in vectoral notation.

$$
\bar{C} 1=\left(\begin{array}{c}
x_{C 1} \\
y_{C 1} \\
z_{C 1}
\end{array}\right)=\left(\begin{array}{c}
\cos (\psi) \cdot x_{C 1} 2^{-\sin (\psi) \cdot y_{C 1}} \\
\sin (\psi) \cdot x_{C 1} 2+\cos (\psi) \cdot y_{C 1} \\
\frac{d_{b 1}}{2 \cdot \cos \left(\theta_{1}\right)}
\end{array}\right)
$$

$$
\overline{\mathrm{C} 2}=\left(\begin{array}{c}
\mathrm{x}_{\mathrm{C} 2} \\
\mathrm{y}_{\mathrm{C} 2} \\
\mathrm{z}_{\mathrm{C} 2}
\end{array}\right)=\left(\begin{array}{c}
\cos (\psi) \cdot \mathrm{x}_{\mathrm{C} 2} 2^{-\sin (\psi) \cdot \mathrm{y}_{\mathrm{C} 2 \_2}} \\
\sin (\psi) \cdot \mathrm{x}_{\mathrm{C} 2 \_2}+\cos (\psi) \cdot \mathrm{y}_{\mathrm{C} 2 \_2} \\
\mathrm{a}-\frac{\mathrm{d}_{\mathrm{b} 2}}{2 \cdot \cos \left(\theta_{2}\right)}
\end{array}\right)
$$

With the pitch points and the direction vectors of the paths of contact, important characteristic data for the mesh geometry have already been defined. In the next step, the face toothing is concretized, which is used as the common generating source profile $\mathrm{Q}$ for both gears.

\subsection{Generating profile $Q$}

The direction vectors of the paths of contact are known as unit vectors. They are perpendicular to the flank surfaces of the generating profile Q. The index "q" is used to identify all quantities that refer to the generating profile. In the first step, the pressure angle in the normal section can be derived.

$$
\alpha_{q n}=\operatorname{asin}\left(e_{t 1 z}\right)
$$

Since the generating profile $\mathrm{Q}$ is to be regarded as a manufacturing tool, alternative pitch circles and helix angles are created. The pitch circle helix angles of wheels 1 and 2 as a function of the vectors $\overline{\mathrm{e}}_{\mathrm{t} 1}$ and $\overline{\mathrm{e}}_{\mathrm{t} 22}$ are calculated according to equations (22) and (23).

$$
\begin{aligned}
& \beta_{q 1}=\operatorname{atan}\left(\frac{e_{t 1 x}}{e_{t 1 y}}\right) \\
& \beta_{q 2}=\operatorname{atan}\left(\frac{e_{t 2 y 2}}{e_{t 2 x 2}}\right)
\end{aligned}
$$

The pitch points $\mathrm{C} 1$ and $\mathrm{C} 2$ define the rolling behaviour of the tooth profiles when considering plane face sections. The rack profiles of the source profile generate the wheel flanks. This leads to the calculation equations for the pitch circles.

$$
\begin{gathered}
d_{q 1}=2 \cdot z_{C 1} \\
d_{q 2}=2 a-2 \cdot z_{C 2}
\end{gathered}
$$

With this the modulus $\mathrm{m}_{\mathrm{tq} 1,2}$ in the face section of the respective gear teeth in the generating profile $Q$ using the number of teeth is determined.

$$
\begin{aligned}
& m_{t q 1}=\frac{d_{q 1}}{z_{1}} \\
& m_{t q 2}=\frac{d_{q 2}}{z_{2}}
\end{aligned}
$$

Furthermore, the modulus can be converted to the normal section in the generating profile $\mathrm{Q}$.

$$
m_{n q 1}=m_{t q 1} \cdot \cos \left(\beta_{q 1}\right)=m_{n q}
$$




$$
m_{\mathrm{nq} 2}=m_{\mathrm{tq} 2} \cdot \cos \left(\beta_{\mathrm{q} 2}\right)
$$

The mean diameters can be defined according to equation (30) by specifying the profile shift factor of a gearing partner (here for gear 1).

$$
\begin{gathered}
d_{m q 1}=d_{q 1}+2 \cdot x_{q 1} \cdot m_{n q} \\
d_{m q 2}=2 \cdot a-d_{m q 1}
\end{gathered}
$$

The profile shift factor $\mathrm{x}_{2}$ for wheel 2 in profile $\mathrm{Q}$ can now be determined from the mean circle diameter and the pitch circle diameter of the generating profile.

$$
x_{q 2}=\frac{d_{m q 2}-d_{q 2}}{2 \cdot m_{n q}}
$$

By specifying the addendum and dedendum factors, the corresponding tip and root diameters of gear 1 and gear 2 can be determined on the basis of this reference profile. The tooth thickness in the normal section $\mathrm{s}_{\mathrm{nq}}$ and the tooth thickness in the face section $\mathrm{s}_{\mathrm{tq} 1,2}$ can be determined from the parameters of the generating profile Q. If the axis crossing angle $\Sigma+\psi$ is changed, adjusted parameters for the generating profile $Q$ and all parameters derived from it result. In particular this is the profile shift factor $\mathrm{x}_{\mathrm{q} 2}$, so that the nominal toothing is always calculated backlash-free.

\subsection{Start and end of the path of contact}

The meshing begins at point $\mathrm{A}$ with the contact of the tooth tip of gear 2 in the foot area of gear 1 and ends at point $E$ with the contact of the tooth tip of gear 1 in the foot area of gear 2. The positions of point $A$ and $E$ in the three views of the gearbox are shown in Figure 5.

To determine the coordinates of the points $\mathrm{A}$ and $\mathrm{E}$, the profile angles at the tip diameter are first required for wheels 1 and 2 according to equation (33) and (34).

$$
\begin{aligned}
& \alpha_{a 2 A}=\operatorname{acos}\left(\frac{d_{b 2}}{d_{a 2}}\right) \\
& \alpha_{a 1 E}=\operatorname{acos}\left(\frac{d_{b 1}}{d_{a 1}}\right)
\end{aligned}
$$

In the face section of wheel 2, point A relative to system 2 can be calculated as follows.

$$
\begin{gathered}
x_{A \_2}=\frac{d_{a 2}}{2} \cdot \sin \left(\theta_{2}-\alpha_{a 2 A}\right) \\
z_{A \_2}=a-\frac{d_{a 2}}{2} \cdot \cos \left(\theta_{2}-\alpha_{a 2 A}\right) \\
{ }_{C} \text { 1_2 }=a-z_{C 1}
\end{gathered}
$$

$$
y_{A \_2}=y_{C 1}{ }+\frac{{ }^{z} C 1 \_2^{-z} A \_2}{e_{t 2 z 2}} \cdot e_{t 2 y 2}
$$

These coordinates are to transform into global system according to equation (39).

$$
\bar{A}=\left(\begin{array}{c}
x_{A} \\
y_{A} \\
z_{A}
\end{array}\right)=\left(\begin{array}{c}
\cos (\psi) \cdot x_{A} \_2-\sin (\psi) \cdot y_{A} \_2 \\
\sin (\psi) \cdot x_{A} \_2+\cos (\psi) \cdot y_{A} \_2 \\
a-\frac{d_{a 2}}{2} \cdot \cos \left(\theta_{2}-\alpha_{a 2} A\right)
\end{array}\right)
$$

Analogous to this procedure, point $\mathrm{E}$ is calculated in the face section of gear 1 and thus directly in global coordinates.

$$
\begin{aligned}
& y_{E}=\frac{-d_{a 1}}{2} \cdot \sin \left(\theta_{1}-\alpha_{a 1 E}\right) \\
& z_{E}=\frac{d_{a 1}}{2} \cdot \cos \left(\theta_{1}-\alpha_{a 1 E}\right) \\
& x_{E}=x_{C 1}+\frac{y_{E}-y_{C 1}}{e_{t 1 y}} \cdot e_{t 1 x}
\end{aligned}
$$

\subsection{Theoretical overlap}

The length of the path AE represents the path of contact $\mathrm{g}_{\mathrm{AE}}$, which can be calculated according to equation (43).

$$
g_{A E}=\sqrt{\left(x_{A}-x_{E}\right)^{2}+\left(y_{A}-y_{E}\right)^{2}+\left(z_{A}-z_{E}\right)^{2}}
$$

The base pitch in normal section results in the corresponding overlap of the gear unit.

$$
\begin{gathered}
p_{\text {enq }}=\pi \cdot m_{n q} \cdot \cos \left(\alpha_{q n}\right) \\
{ }^{\varepsilon} A E=\frac{g_{A E}}{p_{e n q}}
\end{gathered}
$$

The calculation of the theoretical overlap according to this new method provides the same results as the VDI 2736 if the considered gearing has a pitch point. The new method generally considers any axis crossing angle as well as gear pairings.

\subsection{Hertzian pressure, sliding paths and efficiencies}

After clarifying the basic meshing geometry with the contact path $\mathrm{AE}$, the local flank parameters, the pressure according to the Hertzian theory, the local flank velocities, the sliding paths and the efficiencies can be derived in all meshing positions of the gear.

For the numerical analysis, it is advisable to pass through the contact area with a parameter $\mathrm{f}$ and $0 \leq \mathrm{f} \leq 1$. $\mathrm{f}=0$ considers the beginning of the contact path $\mathrm{A}$ and for $\mathrm{f}=1$ the end $\mathrm{E}$. 


$$
\overline{F(f)}=\left(\begin{array}{l}
x_{F}(f) \\
y_{F}(f) \\
z_{F}(f)
\end{array}\right)=\left[\begin{array}{l}
f \cdot x_{E}+(1-f) \cdot x_{A} \\
f \cdot y_{E}+(1-f) \cdot y_{A} \\
f \cdot z_{E}+(1-f) \cdot z_{A}
\end{array}\right]
$$

This function can be used to analyse the local contact conditions at any location in the contact area. In the face section of wheel 1 , the radius of curvature is as follows

$$
\rho_{\mathrm{t} 1}(f)=\frac{\sqrt{4\left(\mathrm{y}_{\mathrm{F}}(\mathrm{f})^{2}+z_{\mathrm{F}}(\mathrm{f})^{2}\right)-d_{\mathrm{b} 1}{ }^{2}}}{2 \cdot \cos \left(\beta_{\mathrm{b} 1}\right)}
$$

The flank surface has two main directions of curvature at the contact point. A main radius of curvature with involute flanks is always infinitely large. The other can be calculated from the radius of curvature in the face section and the given angle. For space reasons, not all equations to be used can be printed here.

Many equations are completely identical to corresponding calculations on spur gear pairs with parallel axes, some are to be derived specifically from the previous definitions in this article or transferred analogously.

After the analysis of the flank curvatures in the contact point, the Hertzian pressure can be calculated as a result of the normal force. Local velocities are obtained for the flank points and sliding paths can be derived in relation to the Hertzian contact ellipses to determine the influence of geometry on wear behaviour.

With knowledge of the tooth pair stiffness, the distribution of the resulting tooth normal force on tooth pairs in the multiple contact area can be calculated. With existing tooth friction coefficients, efficiencies of the gear for both driving directions can also be calculated.

\subsection{Results of sample calculations}

For exemplary calculations, the procedures according to VDI 2736 are to be used to determine the Hertzian pressures, the safety factors and efficiencies in order to make the results accessible for comparison.

The calculation procedure is used for the crossed helical gear unit specified as reference geometry for the testing of crossed helical gear pairs according to VDI 2736-4 with the ratio $i=40 / 1$. First, the geometry parameters are calculated for the gear pair. These allow the calculation of the load capacity as well as the efficiency for the axis crossing angle $\Sigma=90^{\circ}$ according to VDI 2736. Deviating helix angles for gear wheel 2 are analysed according to the presented calculation procedure.

According to VDI 2736, the gearing has an axis crossing angle of $\Sigma=90^{\circ}$ as well as a pitch point in the face section of gear 1 and gear 2 due to the fact that the sum of the helix angles of gear wheel 1 and 2 equals the axis crossing angle. In the initial condition, the pitch points coincide so the gearing has a pitch point according to Niemann's description. The safety with regard to exceeding the permissible load characteristic value, tooth fracture and flank fracture as well as the efficiency can be determined according to VDI 2736. As an extension of this calculation, the helix angle of the gear wheel $2 \beta_{2}$ is varied to show the potential that can be achieved with regard to the change in overlap, pressure, sliding path and stiffness. The change of the helix angle does cause only slightly changes of the geometry sizes according to the described calculation procedure, which can be seen in the profile shift factor $\mathrm{x}_{2}$ of the wheel. In this case, there is no pitch point of the gearing, so that different pitch points result in the face sections for gear 1 and gear 2 as shown in Fig. 5. If the profile shift factor of a wheel for modified helix angles is specified for profile Q, a resulting profile shift factor of the meshing gear and the derivation of new geometric variables related to the generating profile result. This has a corresponding effect on the diameter of the pitch cylinder and the helix angle at the pitch cylinder of gear 1 and gear 2. In addition to the constant transmission behaviour, the change in the helix angle also influences the overlap, the pressures, the sliding paths and the tooth stiffness.

The analysis of the gearing results in a range from $\beta_{2}=7.507^{\circ}-2.5^{\circ}$ to $\beta_{2}=7.507^{\circ}+2^{\circ}$. In this range solutions can be found in order to obtain positive effects on the pressing or sliding paths. By changing the helix angle, the position of the contact ellipse changes according to Hertzian theory. This is shown for the angles $-2.5^{\circ}$, the initial state $\beta_{2}=7.507^{\circ}$ and $+2^{\circ}$ in Figure 6 . With a bigger helix angle, larger contact areas are created along the tooth width.

This has a direct positive effect on Hertzian pressure, since the force to be transmitted is distributed over the larger contact area. For these calculated helix angles, the relevant geometry and calculation values are shown as initial values in Table 1 . 
Table 1. Geometry and calculation parameters for the analysed gear pair

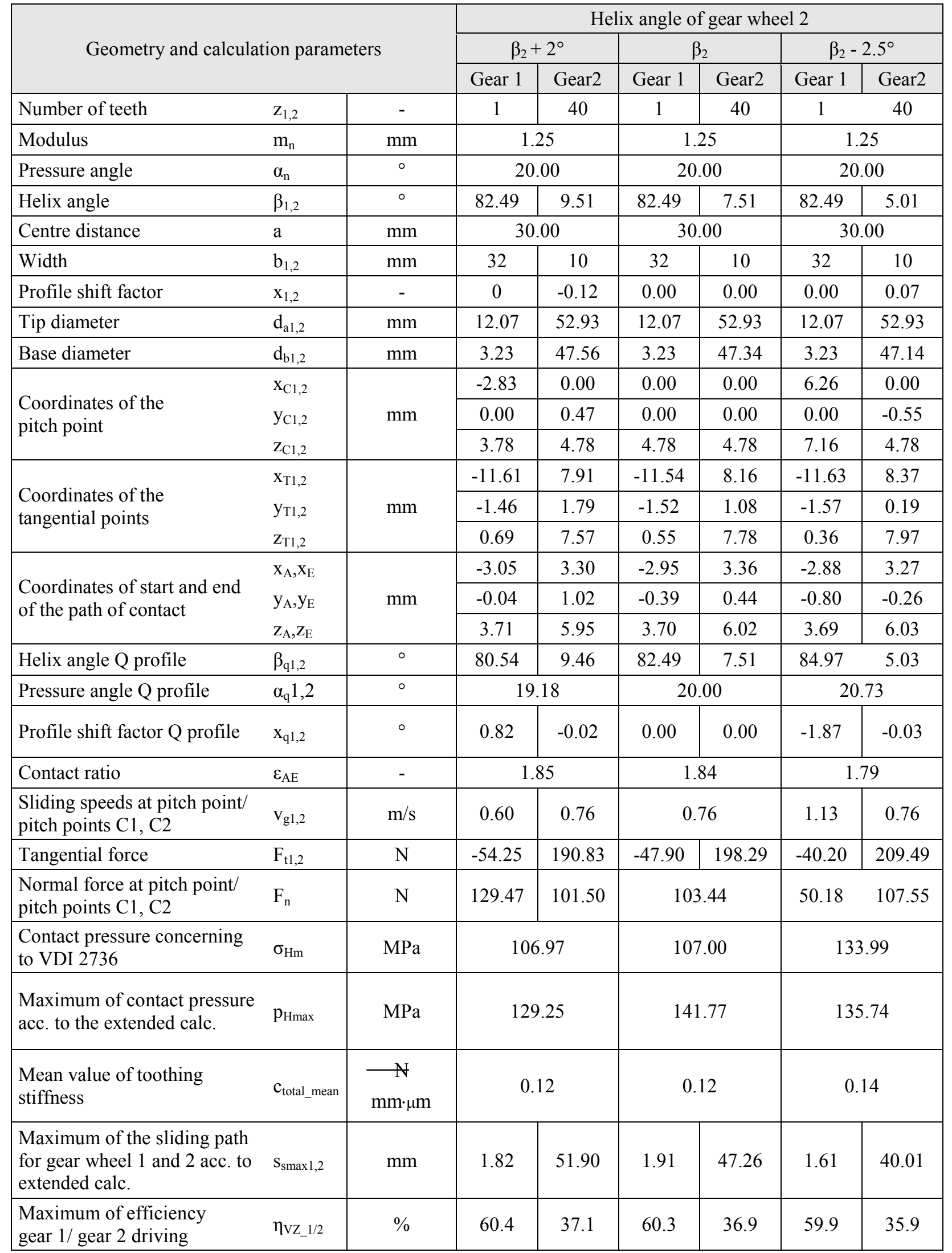




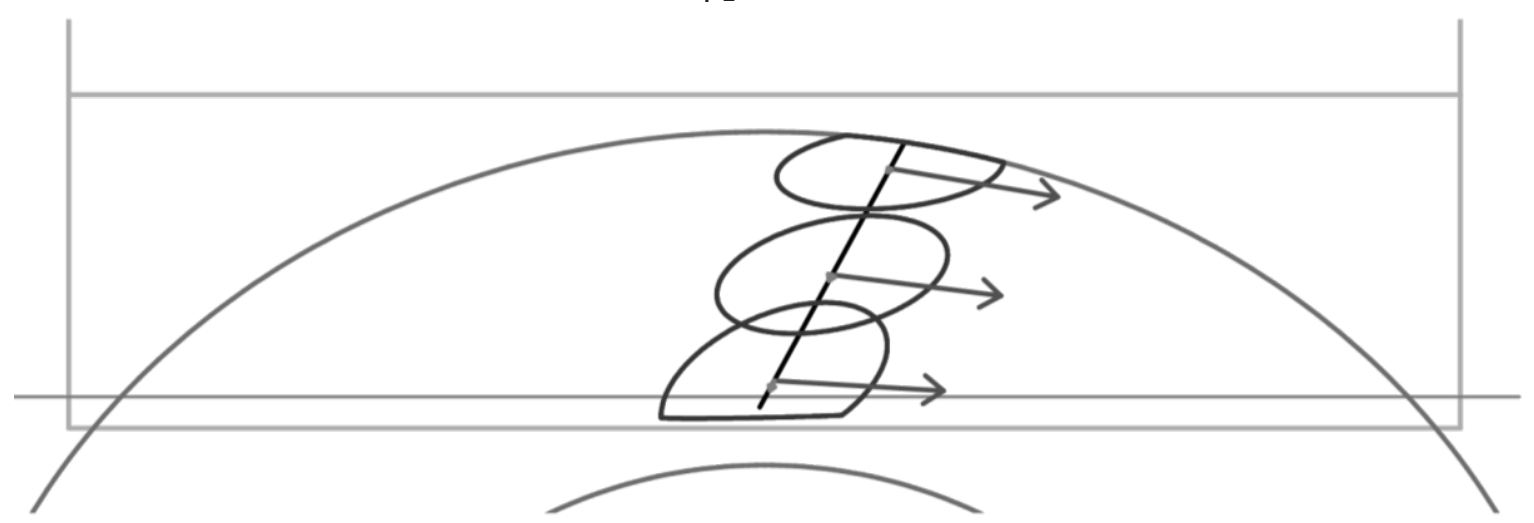

$\beta_{2}=7.507^{\circ}$

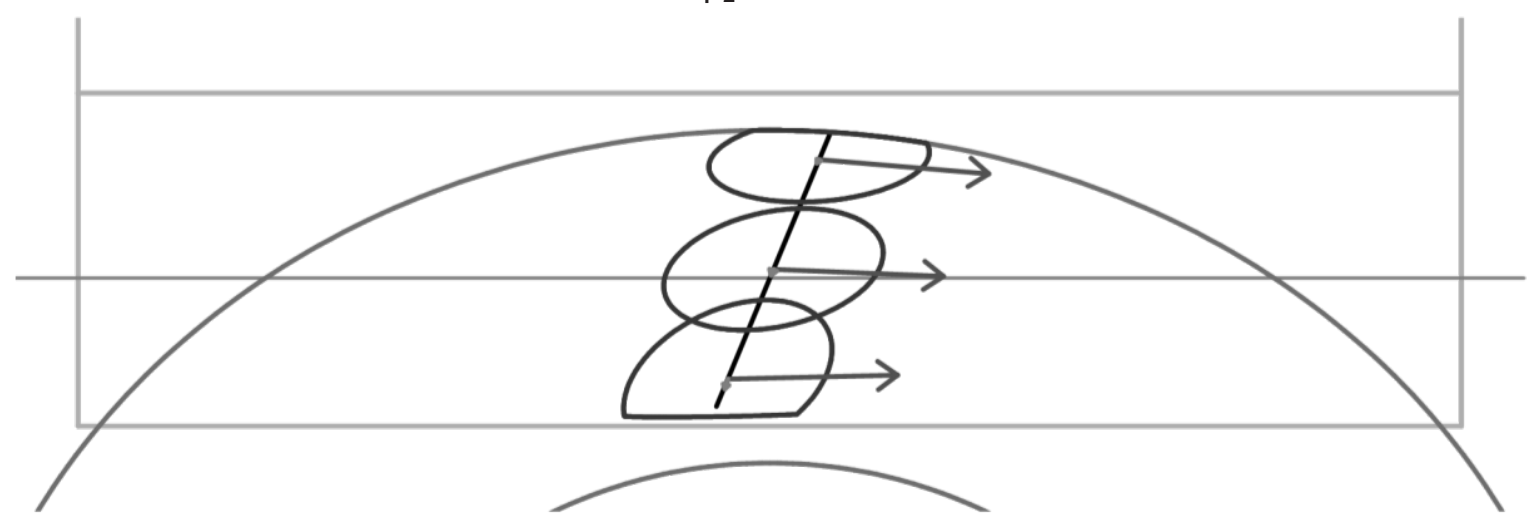

$\beta_{2}=5.007^{\circ}$

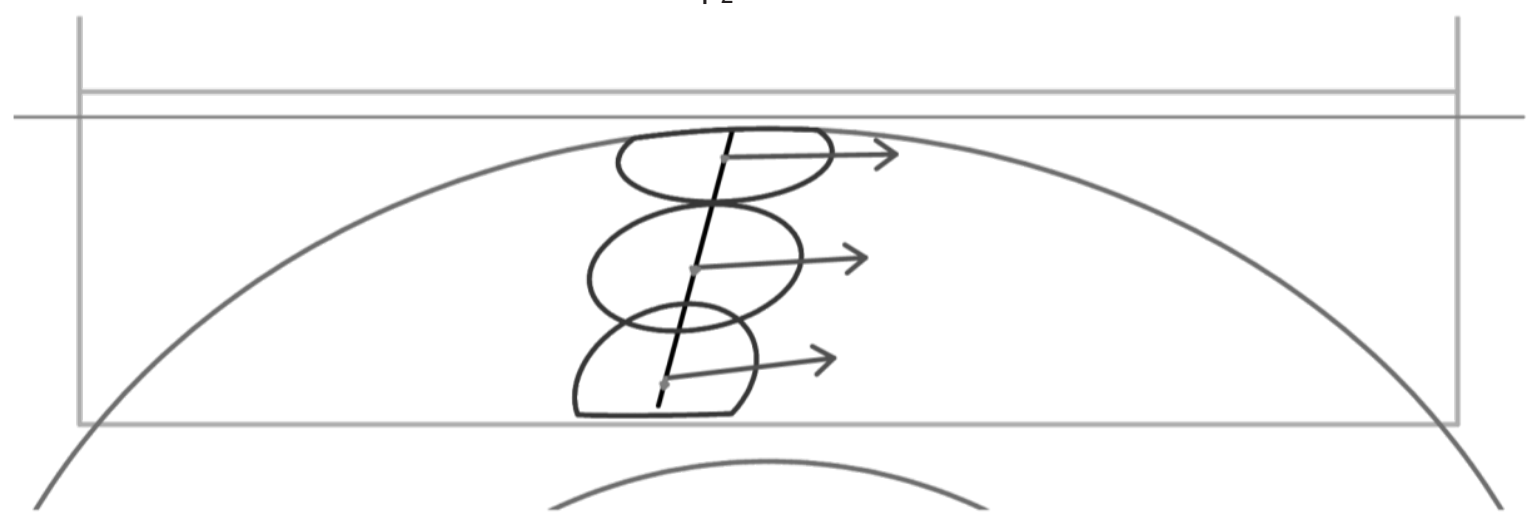

_ Contact ellipsis at various meshing positions

— Gear wheel 1 (worm gear)

\section{_ Gear wheel 2}

- Tangential speed gear wheel 1

_ Tangential speed gear wheel 2

Fig. 6. Contact ellipsis along the path of contact for $\beta_{2}=9.507^{\circ}, \beta_{2}=7.507^{\circ}$ and $\beta_{2}=5.007^{\circ}$

The Hertzian pressures, sliding paths and efficiencies are shown in the following diagrams as a function of the standardized distance of the path of contact $(0 \wedge$ point $\mathrm{A}$, start of contact; $1 \hat{=}$ point $\mathrm{E}$, end of contact). The calculations according to VDI 2736 are only valid for gear pairs with axis crossing angles of $90^{\circ}$ and a pitch point. The results calculated with VDI 2736 are shown only for the sake of completeness. Figure 7 shows the comparison of Hertzian pressures for the same angular positions $\left(\beta_{2}=9.507^{\circ}, \beta_{2}=7.507^{\circ}\right.$ and $\left.\beta_{2}=5.007^{\circ}\right)$ for the three teeth meshing along the path of contact. 

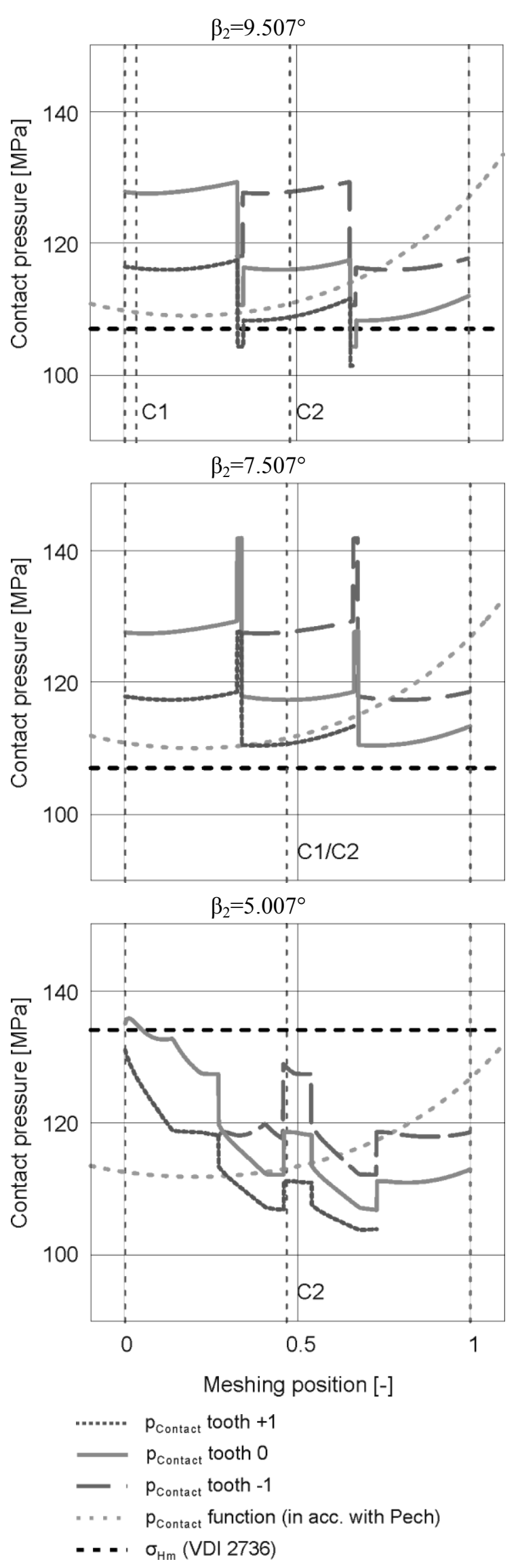

Fig. 7. Hertzian pressure along the path of contact for $\beta_{2}=9.507^{\circ}, \beta_{2}=7.507^{\circ}$ and $\beta_{2}=5.007^{\circ}$
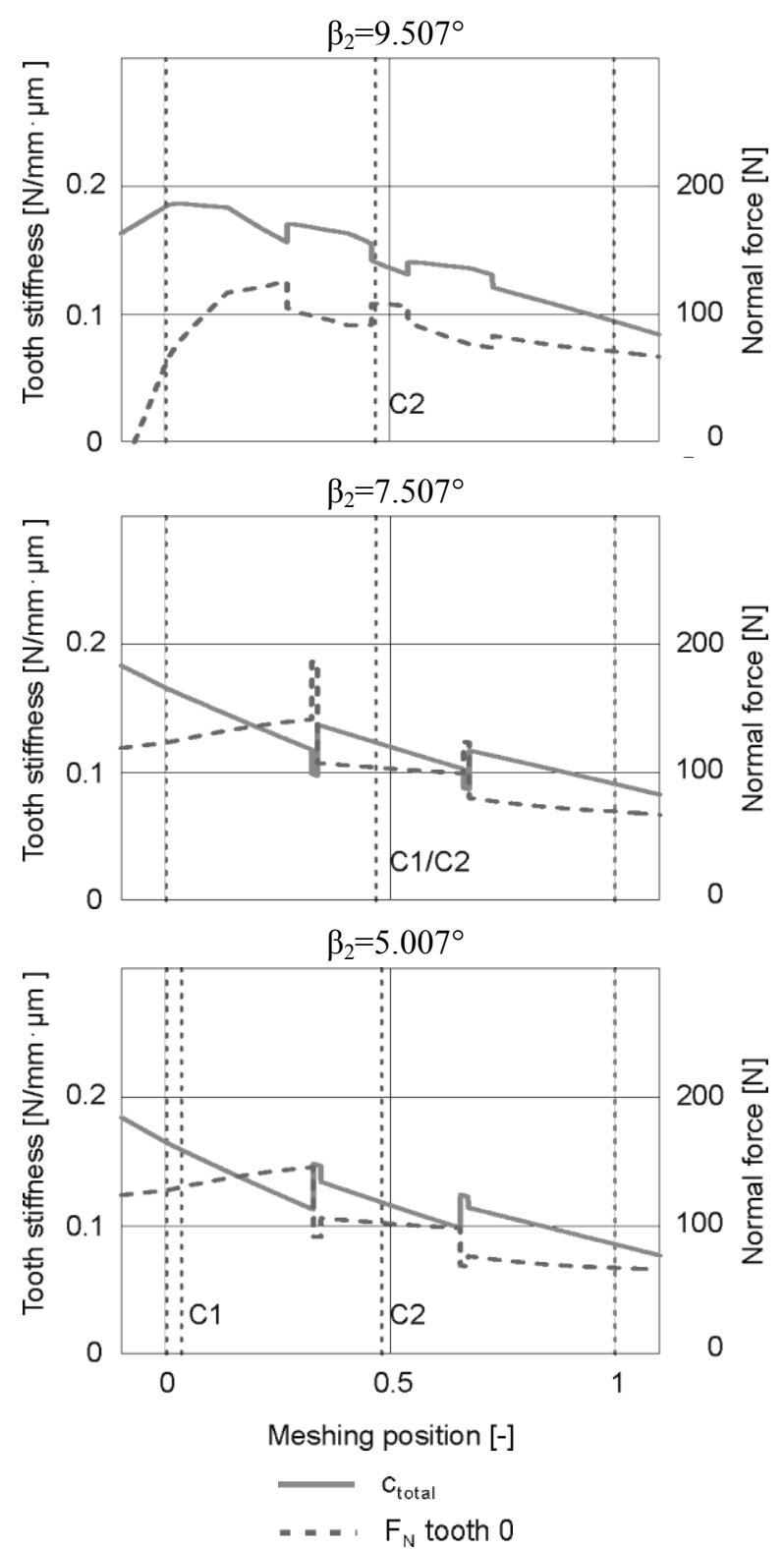

Fig. 8. Normal force and toothing stiffness along the path of contact for $\beta_{2}=9.507^{\circ}, \beta_{2}=7.507^{\circ}$ and $\beta_{2}=5.007^{\circ}$

The pressures resulting from the contact of a pair of teeth along the path of contact are determined considering the stiffness and the overlap ratio as well as the pressure in accordance to the calculation of Pech [3].

Furthermore, the calculation results for the mean flank pressure $\sigma_{\mathrm{Hm}}$ according to VDI 2736 are shown. From the variation of the helix angle $\beta_{2}$ a maximum value of the Hertzian pressure at a helix angle $\beta_{2}=9.507^{\circ}$ lower by $10 \%$ compared to the initial helix angle is achieved in the tooth contact. If the helix angle is varied to $\beta_{2}=5.007^{\circ}$ the maximum of the Hertzian pressure is still $5 \%$ lower compared with the initial angle.

Lower Hertzian pressures are accompanied by a direct increase in the tooth flank load-carrying capacity of the gear pair. 
This also effects the normal contact force and the toothing stiffness, that are shown in Figure 8. Especially the mean value of the toothing stiffness increases about $20 \%$ for $\beta_{2}=5.007^{\circ}$ and there are less discontinuities. This is considered to have a positive effect on the dynamic excitation behaviour.
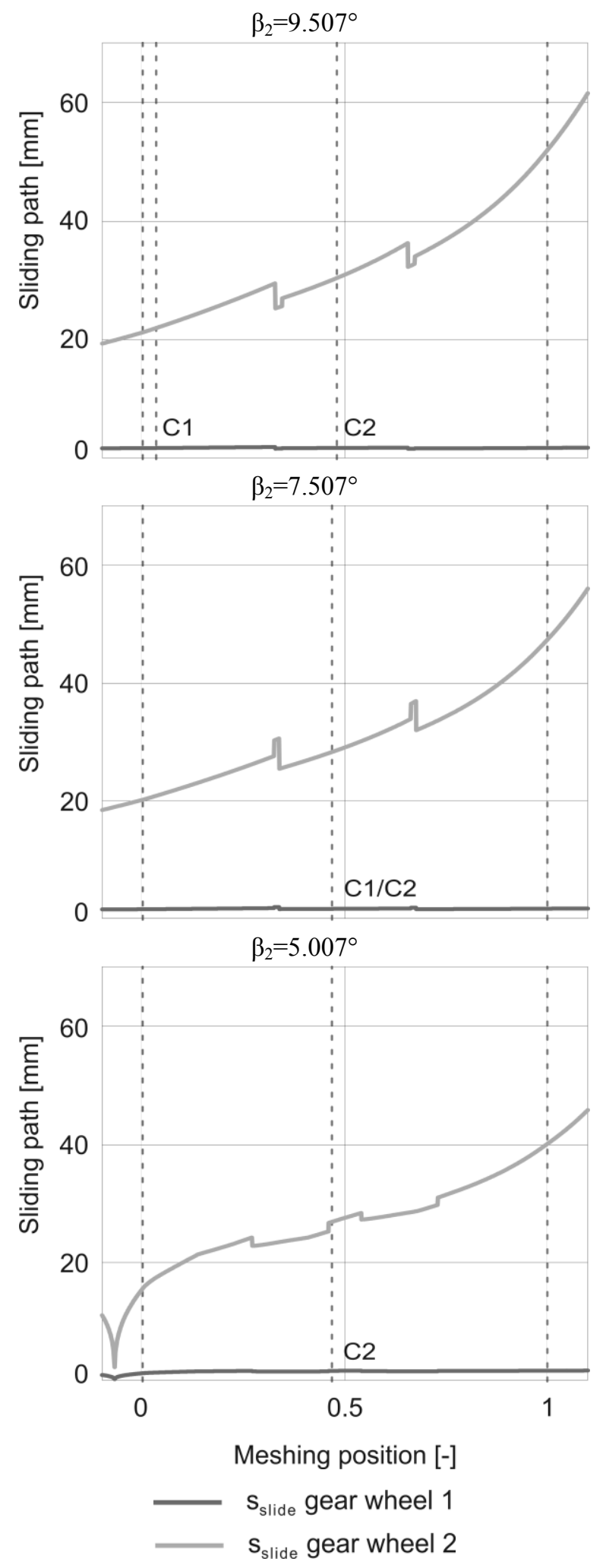

Fig. 9. Sliding paths along the path of contact for $\beta_{2}=9.507^{\circ}, \beta_{2}=7.507^{\circ}$ and $\beta_{2}=5.007^{\circ}$
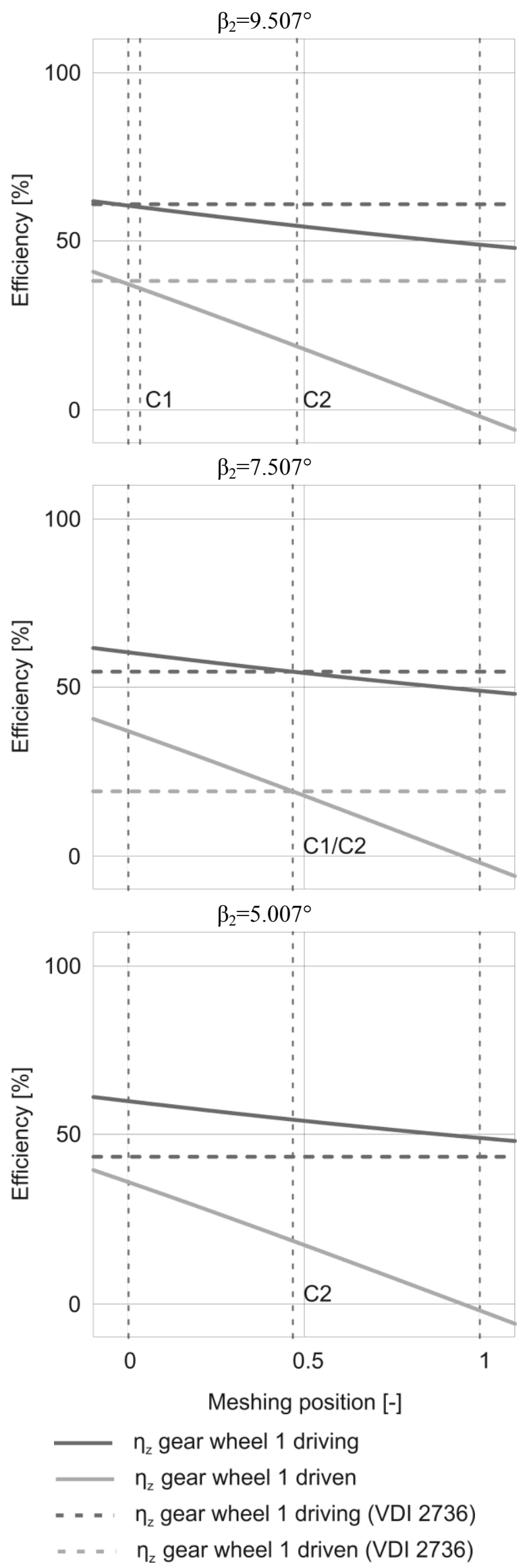

Fig. 10. Efficiencies along the path of contact for $\beta_{2}=9.507^{\circ}$, $\beta_{2}=7.507^{\circ}$ and $\beta_{2}=5.007^{\circ}$ 
The values of the sliding paths decline if the helix angle is varied to $\beta_{2}=5.007^{\circ}$ as shown in Figure 9. In this case the maximum value of the sliding paths for both gears is about $15 \%$ lower compared to the initial helix angle. If the helix angle is varied by $-2^{\circ}$ the maximum of the sliding path increases for the gear 2 about $10 \%$. This can be explained by the magnification of the contact ellipse and the resulting larger contact area with constant sliding speed. Lower sliding paths have a direct positive effect on the wear behaviour of the gearing.

The efficiency of both driving wheel 1 and driving wheel 2 is only slightly affected by the change in the helix angle of gear wheel 2. The calculations show a minimally lower efficiency (approx. 3\%) for the helix angle $\beta_{2}=5.007^{\circ}$ and a slightly higher efficiency for $\beta_{2}=9.507^{\circ}$ (approx. 1\%) for the driving wheel 2 compared with the initial helix angle $\beta_{2}=7.507^{\circ}$.

With the example gearing, the overlap ratio of the gearing is reduced with a smaller helix angle. This has a corresponding effect on the load distribution in the tooth mesh, which is determined based on tooth stiffness. It can be seen that a larger helix angle results in a larger overlap ratio. This has a positive effect on the toothing stiffness, which results directly in a more advantageous excitation behaviour.

The effects shown can be used specifically for new designs of gears in order to achieve higher load carrying capacities or wear resistance of the gears without obtaining significant disadvantages. The efficiencies are virtually unchanged after the change in the helix angle.

\section{Practical comparison of the calculation process and outlook}

Within the context of initial practical investigations, the axis crossing angle was varied using the example of two master gears on a two-flank gear testing machine. A gage worm $\left(\mathrm{m}_{\mathrm{n}}=6.5 \mathrm{~mm}, \alpha_{\mathrm{n}}=20^{\circ}, \gamma_{\mathrm{m}}=5.17^{\circ}\right)$ with a spur gear with straight teeth was meshed with the same modulus and pressure angle. The axis crossing angle, which results from the calculation procedure for this gear pair, deviates from $90^{\circ}$ due to the spur toothing on gear 2. For all examined axis crossing angles, the rolling deviations were recorded accordingly. For the investigation, the axis crossing angle of the wheel pair was changed in $3^{\circ}$ steps in both directions. The comparison of the measurement results shows no discernible differences with regard to the rolling error within the measurement deviation, which can be directly transferred to the transmission behaviour of the wheel pairing. Within these tests, the contact pattern of the wheel pair was also documented. The results are shown in Figure 11. Figures 5 and 6 show the correlation according to which the line of contact is shifted from the wheel centre to the edge of the wheels.

By means of the presented calculation procedures it can be shown for existing gears in which range deviations of the axis crossing angle remain without effect on the transmission behaviour. This allows the definition of tolerances.
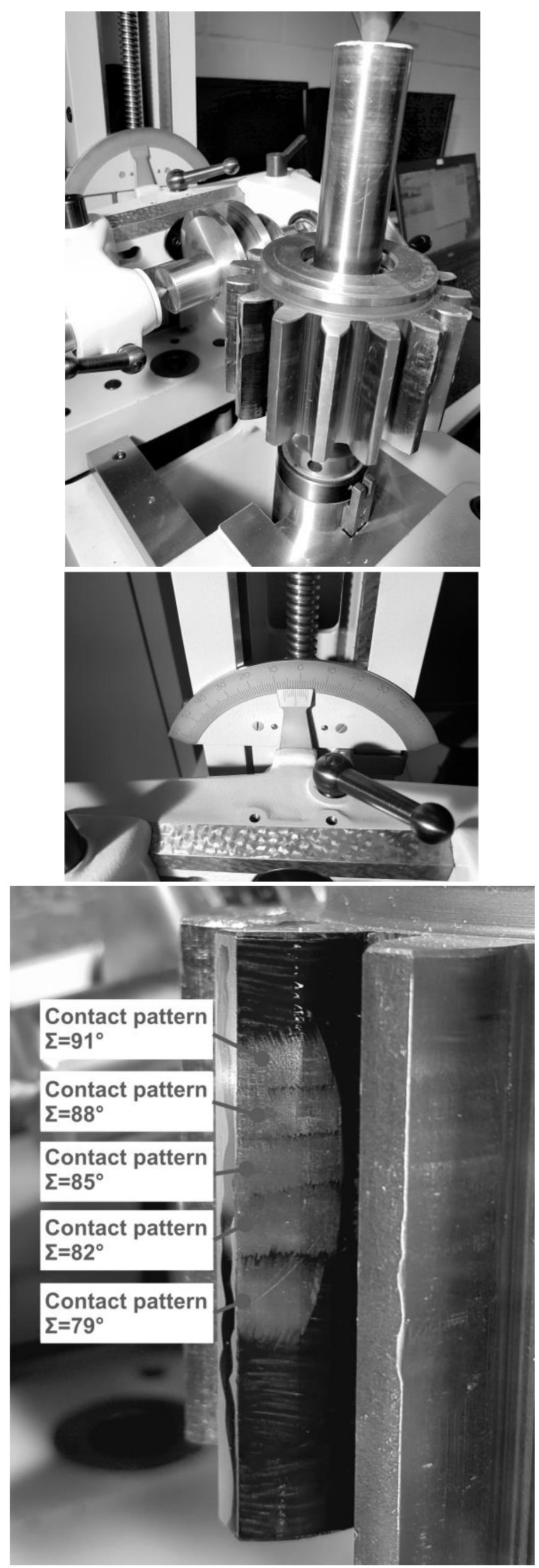

Fig. 11. Measurement via double-flank roller testing and contact patterns resulting from different axis crossing angles 


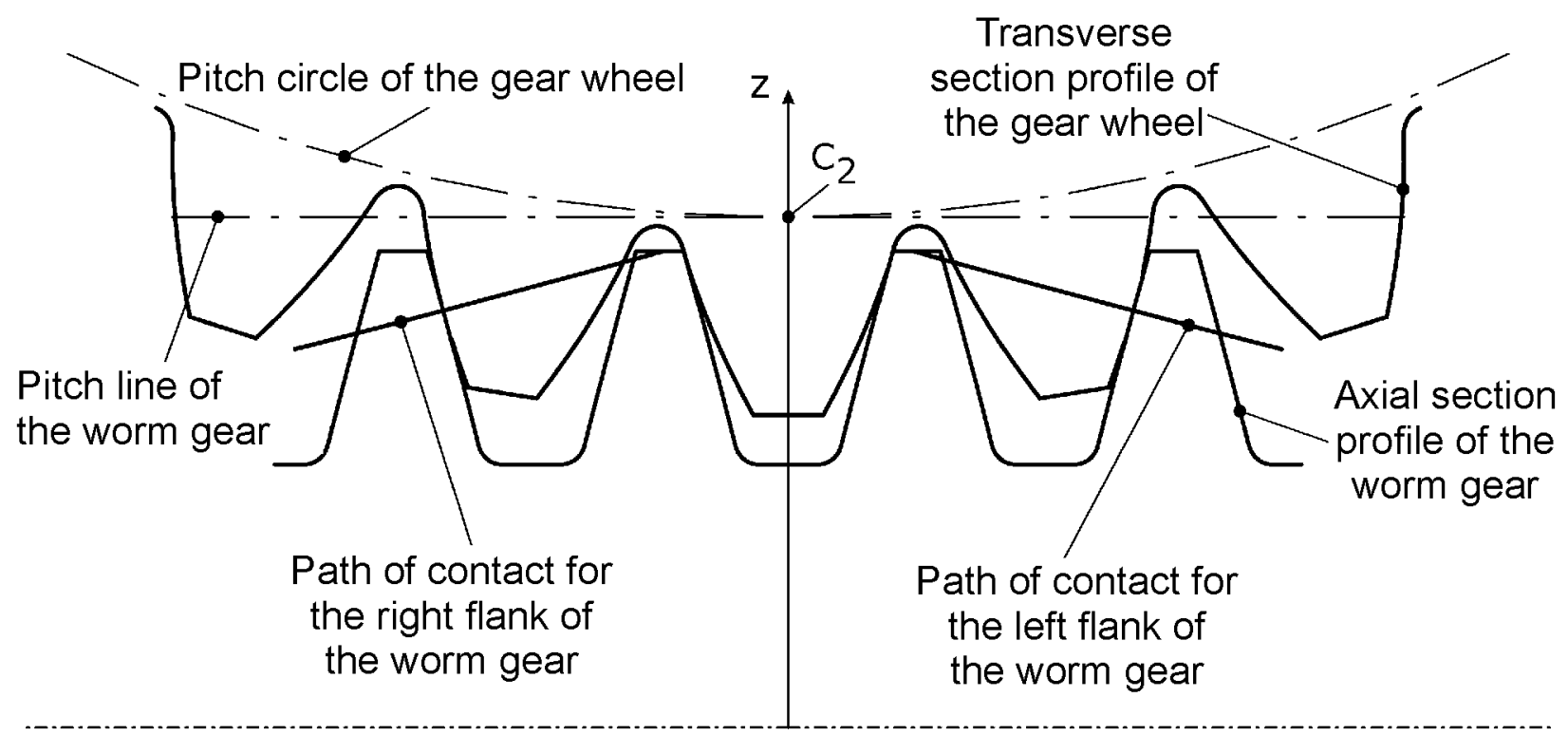

Fig. 12. Axial section for a worm gearbox with a profile shift factor greater than 1

In addition, by changing the axis crossing angle depending on the respective gearing geometry, an improvement in Hertzian pressure and/or glide paths can be achieved, which has a direct effect on the load carrying capacity or wear behaviour of the wheel pairing. Furthermore, the calculation method can be used in the gearing design in order to use straight-toothed gears, to use identical parts to implement changed boundary conditions or to be able to realize any axis crossing angle.

The new calculation method provides the possibility to spatially separate the contact areas of the left and right flanks of the worm gear along the worm axis. Figure 12 shows this case using the example of a worm gearing with a ZI profile and a profile shift factor greater than 1 . The profile of the worm and the wheel profile in the worm axis section are shown. The pitch line of the worm, the pitch circle of the wheel and the path of contact for a plane view are also shown.

The figure shows the nominal geometry of the gear with nominal tooth thicknesses. In practice, tooth thickness tolerances are selected which give the desired backlash for the gear unit in order to avoid constraining forces.

The design according to Fig. 12 allows the tooth thickness dimensions greater than 0 to be selected. The tooth geometries then no longer "fit" each other in the operating centre distance. The thicker teeth must avoid contact with the mating tooth. The teeth of the worm in the contact area must bend outwards and the teeth of the gear inwards.

In the load-free state of the gear unit, this leads to an elastic preload in the gear unit. The gearbox has a minimum radial force that can never be undercut. The magnitude of this force depends on the tooth thickness selected and the tooth pair elasticities.

If a torque is applied to the wheel, the tooth pairs of the load flank are additionally deformed and the tooth pairs with rear flank contact are relieved until the flanks are finally lifted.

The rear flanks are free under nominal load. The gear unit achieves the same load carrying capacity under load. The rigidity of the gear unit increases.

In rolling bearings, a controlled elastic preload leads to improved noise behaviour. Such an effect can also be assumed for crossed-axis helical gear pairs. The effect is achieved by design parameters and does not increase the cost of the components.

The calculation method presented in this article can be used first of all to analyse a crossed-axis helical gear pair more detailed than by means of the VDI 2736 or similar methods. Furthermore tolerances for manufacturing and mounting can be determined for crossed helical gear boxes, using the results of the new method. As shown in the exemplary results gear pairs with optimized Hertzian contact pressures an sliding paths can be designed to increase the load carrying capacity of the gears.

\section{References}

1. G. Niemann, H. Winter, Maschinenelemente Band IIII, Springer-Verlag, Berlin, Heidelberg, New York, Tokyo (1960)

2. Verein Deutscher Ingenieure: VDI 2736: Thermoplastische Zahnräder Blatt 1-4, Beuth Verlag, Berlin (2014/2016)

3. M. Pech, Tragfähigkeit und Zahnverformung von Schraubradgetrieben der Werkstoffpaarung Stahl/Kunststoff, Dissertation Ruhr-University Bochum, Bochum (2011)

4. J. Wassermann, Einflussgrößen auf die Tragfähigkeit von Schraubradgetrieben der Werkstoffpaarung Stahl/Kunststoff, Dissertation Ruhr-University Bochum, Bochum (2005) 
5. J. Sucker, Entwicklung eines Tragfähigkeitsberechnungsverfahrens für Schraubradgetriebe mit einer Schnecke aus Stahl und einem Rad aus Kunststoff, Dissertation RuhrUniversity Bochum, Bochum (2012)

6. A. Shimokohbe; A. Toyama; L. Qi-Jun, Improvement in Load Capacity of Crossed Helical Gears, Gear Technology, pp. 34-48 (1987)

7. O. Alipiev, Method of geometric calculation of involute helical gear drives, modified in two directions, International Journal of Engineering, pp.81-88 (2010) 